Microrganismos associados ao tratamento de águas de abastecimento com coagulante orgânico vegetal (tanato quartenário de amônio)...

\title{
MICRORGANISMOS ASSOCIADOS AO TRATAMENTO DE ÁGUAS DE ABASTECIMENTO COM COAGULANTE ORGÂNICO VEGETAL (TANATO QUATERNÁRIO DE AMÔNIO) - I. MICRORGANISMOS FILAMENTOSOS.
}

\section{Microorganism associated to the drinking water treatment with vegetal organic coagulant (Quaternary Ammonium Tannate) - I. Filamentous Microorganism}

\author{
M. A. Castro-Silva ${ }^{1}$ \\ L R. Rörig ${ }^{1}$ \\ L H. Lamb ${ }^{2}$ \\ C. A. Heck $^{2}$ \\ O. G. Decusati ${ }^{2}$
}

\section{Resumo}

Os taninos são moléculas fenólicas biodegradáveis que podem ser aplicadas no tratamento de esgotos e de águas destinadas ao consumo humano, nos processos de coagulação e floculação. Esta biodegradabilidade, apesar de benéfica, pode resultar no crescimento excessivo de microrganismos, prejudicando as operações de manutenção da estação. Neste contexto, o presente trabalho teve como objetivo a caracterização da comunidade de microrganismos filamentosos presentes na estação de tratamento da água do Município de Brusque, na qual foi utilizado experimentalmente um coagulante/floculante a base de tanino, o Tanato Quaternário de Amônio. Durante a aplicação do coagulante, quatro práticas, objetivando o controle do crescimento microbiano, foram avaliadas Estas práticas corresponderam à aplicação de dióxido de cloro, de hipoclorito de sódio, de um agente alcalinizante e limpeza dos decantadores. Nas amostras analisadas, a bactéria Sphaerotilus natans foi identificada com sendo o organismo mais abundante na estação, sendo a sua abundância maior nas amostras obtidas do filtro de areia e carvão. Das práticas avaliadas, a aplicação de hipoclorito de sódio foi a mais eficiente no controle da proliferação dos microrganismos filamentosos nos diferentes estágios de tratamento, podendo ser adotada como medida mitigadora do crescimento microbiano. Os resultados sugerem a realização de experimentos em condições controladas, com a finalidade de elucidar os mecanismos pelos quais o Tanato Quaternário de Amônio estimula crescimento dos microrganismos.

Palavras-chave: Sphaerotilus natans; Estação de Tratamento de Água; Tanato Quaternánio de Amônio.

Laboratório de Microbiologia Aplicada (LAMA) - CTTMar - UNIVALI - Rua Uruguai, 458. CEP: 88.302-202, Itajaí - SC - Brasil. Email: marcusadonai@cttmar.univali.br

2 TANAC SA - T. Weibull, 199. CEP: 95.780-000, Montenegro - RS - Brasil. 


\section{Abstract}

Tannines are biodegradable phenolic compounds that can be used in the wastewater or drinking water treatment, in the processes of coagulation and flocculation. Besides being useful, this biodegradability can cause excessive proliferation of microorganisms, preventing the management of the treatment plant. In this context, this work had the objective of characterization of filamentous microorganisms from drinking water treatment plant of Brusque, in which a tannine based compound, Quaternary Ammonium Tannate, was applied as a coagulant/floculant. During its application, four management practices for controlling the microbial growth were evaluated. These practices were the application of chlorine dioxide, sodium hipochloride, and an alkalinization agent, and clean-up of the sedimentation tanks. In the samples analized, the bacterium Sphaerotilus natans was identified as the most abundant organism in the treatment plant, its abundance being higher in the samples of the coal/sand filter. Considering the practices evaluated, application of sodium hypochloride was the most efficient in the control of filamentous microorganisms proliferation in the different stages of the treatment plant, being effective to be adopted in the mitigation of microbial growth. The results sugest the realization of experiments in controlled conditions, to elucidate how the Quaternary Ammonium Tannate gives suport to the growth of microorganisms.

Keywords: Sphaerotilus Natans; Drinking Water Treatment Plant; Quaternary Ammonium Tannate.

\section{Introdução}

Os taninos são moléculas fenólicas, encontradas nas formas de monômeros, oligômeros ou polímeros, que possuem a capacidade de formar complexos com proteínas e outras macromoléculas e minerais. Estes compostos possuem várias aplicações, as quais incluem o curtimento de peles animais e no tratamento de esgotos e de águas destinadas ao consumo humano (TANAC, 2003).

No tratamento de esgoto e de águas para o consumo, os taninos podem ser aplicados nos processos de coagulação e floculação, os quais são responsáveis pela remoção de partículas, como minerais, sólidos inertes e microrganismos. Estas partículas são removidas pela formação de flocos com alta densidade, que são posteriormente decantados. A função do coagulante é a de neutralizar as cargas (normalmente negativas) de repulsão destas partículas, promovendo assim sua coagulação, ou aumento de tamanho, facilitando a sua precipitação (TANAC, 2003).

Tradicionalmente, os agentes coagulantes utilizados são sais metálicos, como o sulfato de alumínio e 0 cloreto de ferro, que além de poderem apresentar toxicidade aos organismos, não são passíveis de serem destruídos biologicamente, podendo persistir na água tratada ou no lodo gerado pela estação (DROSTE, 1997). Em contrapartida, coagulantes orgânicos, como os taninos, apresentam a vantagem de serem moléculas biodegradáveis, sendo destruídas no próprio tratamento.

Apesar de benéfica, esta biodegradabilidade pode resultar no crescimento excessivo de microrganismos presentes na estação de tratamento. Este estímulo à flora microbiana pode ser útil em estações de tratamento de efluentes, pois pode resultar em um aumento na sua eficiência. Porém, no tratamento da água para consumo, o crescimento excessivo pode resultar em colmatação dos diferentes compartimentos da estação, necessitando de operações de manutenção mais freqüentes, aumentando assim o custo do tratamento. Para viabilizar o uso destes coagulantes orgânicos no tratamento da água, é preciso então controlar o crescimento dos microrganismos. Para isso, é de fundamental importância conhecermos os microrganismos presentes nas estações de tratamento, e em que abundância eles são encontrados.

Neste contexto, o presente trabalho teve como objetivo a caracterização da comunidade de microrganismos filamentosos presentes na Estação de Tratamento da Água (ETA) do Município de Brusque (Santa Catarina), na qual foi utilizado experimentalmente um coagulante/floculante a base de tanino, o tanato quaternário de amônio. Durante a aplicação do tanato quaternánio de amônio na ETA foi observado um crescimento excessivo de microrganismos em vários estágios do tratamento. Por isso, também foi avaliada a utilização de agentes biocidas (dióxido de cloro e hipoclorito 
de sódio) e de um agente alcalinizante, como agentes controladores dos microrganismos presentes, e estabelecer o seu potencial para aplicação na estação.

\section{Material e Métodos}

\section{Amostras:}

As amostras analisadas foram provenientes da linha de tratamento de água da ETA de Brusque, tendo sido coletadas em várias condi- ções distintas de tratamento, em épocas distintas (Tabela 1). Nas amostragens realizadas em maio e julho de 2003 foram coletadas amostras provenientes de três pontos da estação: (1) água bruta do Rio Itajaí-Mirim; (2) água dos decantadores e (3) sobrenadante do lodo que se forma sobre os filtros de areia e carvão. Estes três tipos de amostras foram coletados em três situações distintas: após tratamento com dióxido de cloro (A), após tratamento com hipoclorito de sódio (B) e após tratamento com uma agente alcalinizante $(\mathrm{C})$.

\section{Tabela 1 - Descrição das amostras}

\begin{tabular}{ccc}
\hline Amostra & Período & Descrição \\
\hline 1A & Maio/2003 & Água bruta com dióxido de cloro \\
2A & Maio/2003 & Decantador com dióxido de cloro \\
3A & Maio/2003 & Sobrenadante de filtro com dióxido de cloro \\
1B & Maio/2003 & Água bruta com hipoclorito de sódio \\
2B & Maio/2003 & Decantador com hipoclorito de sódio \\
3B & Maio/2003 & Sobrenadante com hipoclorito de sódio \\
1C & Julho/2003 & Água bruta com alcalinizante \\
2C & Julho/2003 & Decantador com alcalinizante \\
3C & Julho/2003 & Sobrenadante de filtro com alcalinizante \\
1D & Setembro/2003 & Parte interna da calha, decantadores 3 e 4 \\
2D & Setembro/2003 & Parte externa da calha, decantador 3 \\
3D & Setembro/2003 & Parte interna da calha, decantador 2 \\
4D & Setembro/2003 & Parte externa da calha, decantador 2 \\
5D & Setembro/2003 & Leito do filtro 4 \\
\hline
\end{tabular}

Em setembro de 2003 foi realizada uma nova amostragem (D), após limpeza profunda dos decantadores com retirada de resíduos de sulfato de alumínio, de outras substâncias e de prováveis inóculos de microrganismos do fundo. Estas amostras foram obtidas dos seguintes pontos: (1), amostra da parte interna da calha dos decantadores $3 \mathrm{e}$ 4, (2), amostra da parte externa da calha do decantador 3, (3), amostra da parte interna da calha do decantador 2, (4) amostra da parte externa da calha do decantador 2, e (5), amostra do leito do filtro 4. Todas as amostras foram coletadas, e mantidas vivas e resfriadas a $4^{\circ} \mathrm{C}$, até o momento da análise.

\section{Análise qualitativa e quantitativa das bactérias:}

Análise de bactérias filamentosas. A análise de bactérias filamentosas foi efetuada utilizando-se uma metodologia adaptada da metodologia para análise dos mesmos organismos em lodos ativados, segundo Vazoller et al. (1989). Esta análise foi realizada em duas fases distintas. Na primeira foi realizada uma avaliação qualitativa, com a finalidade de se determinar espécies ou morfotipos (filamentos com características morfológicas distintas, mas sem denominações taxonômicas) presentes nas amostras. Na segunda, a abundância de 
bactérias filamentosas foi então determinada. Ambas as análises foram efetuadas em amostras não fixadas (in vivo).

$\mathrm{Na}$ análise qualitativa foram determinadas as seguintes características dos filamentos, segundo Murray et al. (1994): morfologia e dimensões do filamento, presença de ramificações, presença de bainha, morfologia e dimensões das células que compõem os filamentos, tipo de movimento (quando móvel), presença de grânulos de enxofre, presença de corpúsculos intracelulares, posição do filamento em relação ao floco e reação de Gram. Os filamentos observados foram classificados segundo Holt (1977) e Gerardi (1990).

$\mathrm{Na}$ análise quantitativa foi determinada a abundância de filamentos, discriminados pelas seguintes classes de tamanhos (em ìm): 0 - 10, 10 - 25, 25 - 50, 50 - 100, 100 - 200, 200 - 400, 400 - 800 e > 800. A quantificação foi realizada com o auxílio de uma Câmara de Sedgewick-Rafter, em uma alíquota de amostra bruta ou, quando necessário, de uma diluição. No total, para cada amostra, foram contadas aproximadamente 100 células. A abundância para cada classe de tamanho foi determinada dividindo-se o número de organismos contados pelo o número de campos da lâmina analisados, e multiplicando-se por 1000 (número total de campos presentes na lâmina). Quando necessário, multiplicou-se, ainda, o valor obtido pelo fator de diluição. Os valores foram expressos em números de filamentos por cem mililitros de amostra.

\section{Resultados}

Análise Qualitativa de Microrganismos Filamentosos. Os resultados da análise qualitativa de microrganismos filamentosos para as amostras analisadas estão mostrados na Tabela 2. As descrições dos microrganismos observados estão mostradas na Tabela 3. Foram observados microrganismos filamentosos em todas as amostras analisadas, excetuando-se as amostras B1 e C1. Os microrganismos observados foram em sua maioria procariontes (bactérias e cianobactérias), porém microalgas filamentosas da classe Chlorophyceae, foram observadas na amostra D2.

\section{Tabela 2 - Ocorrência dos microrganismos filamentosos observados na Estação de Tratamento de Água do Município de Brusque. Para descrição das amostras ver item Material e Métodos.}

\begin{tabular}{|c|c|c|c|c|c|c|}
\hline \multirow{2}{*}{ Organismos } & \multicolumn{6}{|c|}{ Amostras } \\
\hline & A1 $\quad$ A2 $\quad$ A 3 B 1 B2 $\quad$ B3 & $\mathrm{C} 1$ & $\mathrm{C} 2$ & $\mathrm{C} 3$ & D1 D2 & D3 D4 D5 \\
\hline \multicolumn{7}{|l|}{ Sphaerotilus natans } \\
\hline \multicolumn{7}{|l|}{ Saprospira sp. } \\
\hline \multicolumn{7}{|l|}{ Spirochaeta sp. } \\
\hline \multicolumn{7}{|l|}{ Morfotipo 1} \\
\hline \multicolumn{7}{|l|}{ Morfo tipo 2} \\
\hline \multicolumn{7}{|l|}{ Spirillum sp. } \\
\hline \multicolumn{7}{|l|}{ Flexibacter sp. } \\
\hline \multicolumn{7}{|l|}{ Oscillatoria sp. } \\
\hline \multicolumn{7}{|l|}{ Cianobactéria não identificada } \\
\hline Clorophyceae filamentosa & & & & & & \\
\hline
\end{tabular}


Em todas as amostras em que microrganismos filamentosos estiveram presentes foi observada a dominância da bactéria Sphaerotilus natans. Bactérias do gênero Saprospira foram organismos também comumente observados nas amostras analisadas, estando, porém, ausentes nas amostras coletadas em setembro (amostras D).

Dois morfotipos não identificados de bactérias foram observados apenas nas amostras tra- tadas com dióxido de cloro (amostras A). Microrganismos filamentosos fotossintetizantes (cianobactérias e Chlorophyceae) e bactérias dos gêneros Flexibacter e Spirillum, por sua vez, foram observadas somente nas amostras obtidas em setembro (amostras D). As amostras tratadas com hipoclorito e com o agente alcalinizante foram as que apresentaram o menor número de espécies.

Tabela 3 - Características das bactérias filamentosas observadas na ETA.1, S, natans 2, Saprospira sp.; 3, Spirocheta sp.; 4, Morfotipo 1; 5, Morfotipo 2; 6, Spirillum sp.; 7, Flexibacter sp.; 8, Oscillatoria sp.; 9, Cianobactéria não identificada;10, Chlorophyceae, não identificada.

\begin{tabular}{|c|c|c|c|c|c|c|c|c|c|c|}
\hline \multirow{2}{*}{ Característica } & \multicolumn{10}{|c|}{ Organismos } \\
\hline & 1 & 2 & 3 & 4 & 5 & 6 & 7 & 8 & 9 & 10 \\
\hline Comprimento do Filamen to* & $\begin{array}{l}20- \\
400\end{array}$ & 30 & 20 & $>100$ & 105 & - & 50 & $\begin{array}{l}90- \\
800\end{array}$ & 10 & 741 \\
\hline Diâmetro do Filamen to* & 1 & 1 & $<1$ & 0,5 & 0,8 & $<1$ & 1 & $>5$ & 2 & 15 \\
\hline Morfologia da Célula** & $\mathrm{B}$ & $\mathrm{H}$ & Hf & $\mathrm{B}$ & $\mathrm{B}$ & $\mathrm{Hr}$ & $\mathrm{B}$ & $\mathrm{R}$ & A & $\mathrm{R}$ \\
\hline Comprimen to da Célula*** & 3 & ND & ND & ND & $5-8$ & 10 & ND & ND & 2,5 & 29 \\
\hline Ramificações falsas & + & - & - & - & - & - & - & - & - & - \\
\hline Bainha & + & - & - & - & - & - & - & - & - & - \\
\hline Movimento & - & $\mathrm{D}$ & $\mathrm{F}$ & - & + & + & $\mathrm{F}$ & $\mathrm{D}$ & $\mathrm{D}$ & - \\
\hline Grânulos de enxofre & - & - & - & - & - & - & - & - & - & - \\
\hline Corpúsculos intrac elulares & - & - & - & + & - & - & - & - & - & + \\
\hline Posição*** & $\mathrm{FC}$ & $\mathrm{FC}$ & LV & FC & $\mathrm{FC}$ & LV & $\mathrm{FC}$ & $\mathrm{LV} / \mathrm{FC}$ & $\mathrm{FC}$ & $\mathrm{LV} / \mathrm{FC}$ \\
\hline Pigmentação verde (Cl-a) & - & - & - & - & - & - & & + & + & + \\
\hline Reação de Gram & - & - & - & - & - & - & - & ND & ND & ND \\
\hline
\end{tabular}

* medidas em m; ** B, bacilo, $\mathrm{H}$, helicoidal, Hf helicoidal flexível, Hr, helicoidal rígida, $\mathrm{R}$, retangular, $\mathrm{A}$, arredondada; *** não determinado; **** FC = associado ao floco, $\mathrm{LV}=$ de vida livre.

Análise Quantitativa de Microrganismos Filamentosos. Os resultados das análises quantitativas de bactérias estão expostos na Tabela 4. As contagens não foram discriminadas por serem quase exclusivamente de bactérias da espécie $\mathrm{S}$. natans, a única numericamente significante nas amostras observadas. 
Tabela 4 - Abundância de microrganismo filamentosos nas amostrasprovenientes da estação de tratamento de água do Município de Brusque. A abundância de bactérias filamentosas está expressa em número de organismos (filamentos)/mlde amostra,eestá descriminada por classe de tamanbo dos filamentos. Para descrição das amostras ver item Material e Métodos.

\begin{tabular}{|c|c|c|c|c|c|c|c|c|c|c|}
\hline \multirow{2}{*}{ Característica } & \multicolumn{10}{|c|}{ Organismos } \\
\hline & 1 & 2 & 3 & 4 & 5 & 6 & 7 & 8 & 9 & 10 \\
\hline Comprimento do Filamen to* & $\begin{array}{l}20- \\
400\end{array}$ & 30 & 20 & $>100$ & 105 & - & 50 & $\begin{array}{l}90- \\
800\end{array}$ & 10 & 741 \\
\hline Diâmetro do Filamen to* & 1 & 1 & $<1$ & 0,5 & 0,8 & $<1$ & 1 & $>5$ & 2 & 15 \\
\hline Morfologia da Célula** & $\mathrm{B}$ & $\mathrm{H}$ & Hf & $\mathrm{B}$ & B & $\mathrm{Hr}$ & $\mathrm{B}$ & $\mathrm{R}$ & A & $\mathrm{R}$ \\
\hline Comprimento da Célula*** & 3 & ND & ND & $\mathrm{ND}$ & $5-8$ & 10 & ND & ND & 2,5 & 29 \\
\hline Ramificações falsas & + & - & - & - & - & - & - & - & - & - \\
\hline Bainha & + & - & - & - & - & - & - & - & - & - \\
\hline Movimento & - & $\mathrm{D}$ & $\mathrm{F}$ & - & + & + & F & $\mathrm{D}$ & $\mathrm{D}$ & - \\
\hline Grânulos de enxofre & - & - & - & - & - & - & - & - & - & - \\
\hline Corpúsculos intracelulares & - & - & - & + & - & - & - & - & - & + \\
\hline Posição*** & $\mathrm{FC}$ & $\mathrm{FC}$ & LV & FC & FC & LV & $\mathrm{FC}$ & $\mathrm{LV} / \mathrm{FC}$ & $\mathrm{FC}$ & $\mathrm{LV} / \mathrm{FC}$ \\
\hline Pigmentação verde ( $\mathrm{Cl}-\mathrm{a})$ & - & - & - & - & - & - & & + & + & + \\
\hline Reação de Gram & - & - & - & - & - & - & - & ND & ND & ND \\
\hline
\end{tabular}

De forma geral, a abundância foi maior nas amostras obtidas em setembro, após a limpeza da estação (amostras D). A abundância de microrganismos filamentosos foi maior também nas amostras provenientes do filtro de areia (amostras A3, B3, C3), excetuando-se na amostragem de setembro, na qual foi observada maior densidade na amostra da calha dos decantadores 3 e 4 (amostra D1). Nas amostras de água bruta (A1, B1 e C1) foram observadas as menores densidades.

Considerando os tratamentos com biocidas e com 0 agente alcalinizante, todas as amostras obtidas após tratamento com dióxido de cloro apresentaram densidades de bactérias filamentosas superiores aos do tratamento com hipoclorito, sendo estes valores 1200, 17 e 24 vezes maiores, nos pontos 1, 2 e 3, respectivamente. Em relação ao tratamento com agente alcalinizante, a amostra do filtro apresentou densidades de microrganismos filamentosos semelhantes às do tratamento com dióxido de cloro. Nas outras duas amostras, as densidades foram inferiores aos outros tratamentos.

Em relação às análises quantitativas nas amostras D, levando em consideração a origem de cada amostra, a densidade de organismos filamentosos foi superior nos decantadores 3 e 4, como já salientado. Em todos os decantadores, as concentrações de organismos filamentosos foram superiores na parte interna das suas calhas. No filtro foi observada uma alta concentração de microrganismos filamentosos.

\section{Discussão}

A partir das amostras analisadas, pode-se concluir que a bactéria S. natans foi o organismo responsável pelo crescimento excessivo na ETA de Brusque. Esta espécie de bactéria é comumente relatada como causadora de intumescimento em estações de tratamento de efluentes, sendo, nestes locais, favorecida por condições de ausência de oxigênio e excesso de nutrientes, como o nitrogênio (JENKINS et al., 2004).

Em relação aos diferentes estágios da ETA de Brusque, o filtro de areia e carvão, de maneira geral, proporcionou melhores condições para a colonização e desenvolvimento de microrganismos filamentosos. Isto provavelmente foi em função de 
seu sistema de poros facilitar a agregação dos microrganismos, além de o acúmulo de partículas poderem constituir uma fonte de nutrientes.

Considerando os biocidas utilizados para controlar o crescimento dos microrganismos, o mais eficiente foi o hipoclorito de sódio. Porém, o incremento do $\mathrm{pH}$ também teve um bom efeito inibitório sobre o crescimento dos microrganismos filamentosos. O aumento na densidade de microrganismos filamentosos nas amostras obtidas após a limpeza da ETA provavelmente representa condição normal de operação da estação, não tendo esta limpeza efeitos de diminuição das densidades dos microrganismos presentes.

As causas que levam ao crescimento em excesso dos microrganismos podem ser várias. Miettinen et al. (1997) apontam o carbono orgânico dissolvido e os nutrientes inorgânicos, como o fósforo, como agentes controladores do crescimento microbiano em estações de tratamento de água para abastecimento. Além do aumento da concentração de nutrientes limitantes, como o nitrogênio e o fósforo, a presença de condições de baixas concentrações de oxigênio dissolvido nos locais em que o material floculado acumula pode permitir um maior desenvolvimento de microrganismos mais tolerantes a estas condições. Experimentos de laboratório e de campo, em condições controladas, permitirão que estas hipóteses sejam verificadas, e comprovadas ou refutadas.

\section{Referências}

DRO STE, R.L Theory and practice of water and wastewater treatment. New York: Johm Wiley \& Sons, 1997. 800p.

GERARDI, M. H.; HORSFALL, F. L. Wastewater biology: the microlife. Water Environment Federation. 1995. p. 38-46.

HOLT, J. G. The shorter Bergey's manual of determinative bacteriology. Lippincott: Williams \& Wilkins. 1977.

JENKINS, D.; RICHARD, M. G.; DAIGGER, G. T. Manual on the causes and control of activated Sludge Bulking, foaming, and other solids separation Problems. London: Lewis, 2004. $190 \mathrm{p}$.

MIETTINEN, I. T.; VARTIAINEN, T.; MARTIKAINEN, P. J. Phosphorus and bacterial growth in drinking water. Applied and Environmental Microbiology v. 63, n.8, p. 3242-3245, 1997.

MURRAY, R. G. E.; DOETSCH, R. N.; ROBINOW, C. F. Determinative and cytological microscopy. In: GERHARDT, P.; MURRAY, R. G. E.; WOOD, W. A.; KRIEG, N. R. Methods for general and molecular bacteriology. Washington: ASM ,1994.

TANAC. Tanfloc: manual prático para o uso em estações de tratamento de águas de abastecimento. Montenegro: TANAC S.A. , 2003. 122p.

VAZOLLER, R. F.; GARCIA, M. De L A. R.; GARCIA JR., A. D. Microbiologia de lodos ativados. São Paulo,SP: CETESB. 1989. 23 p.

Recebido em/Recived in: 30/09/2003

Aprovado em/Approved in: 01/12/2003 